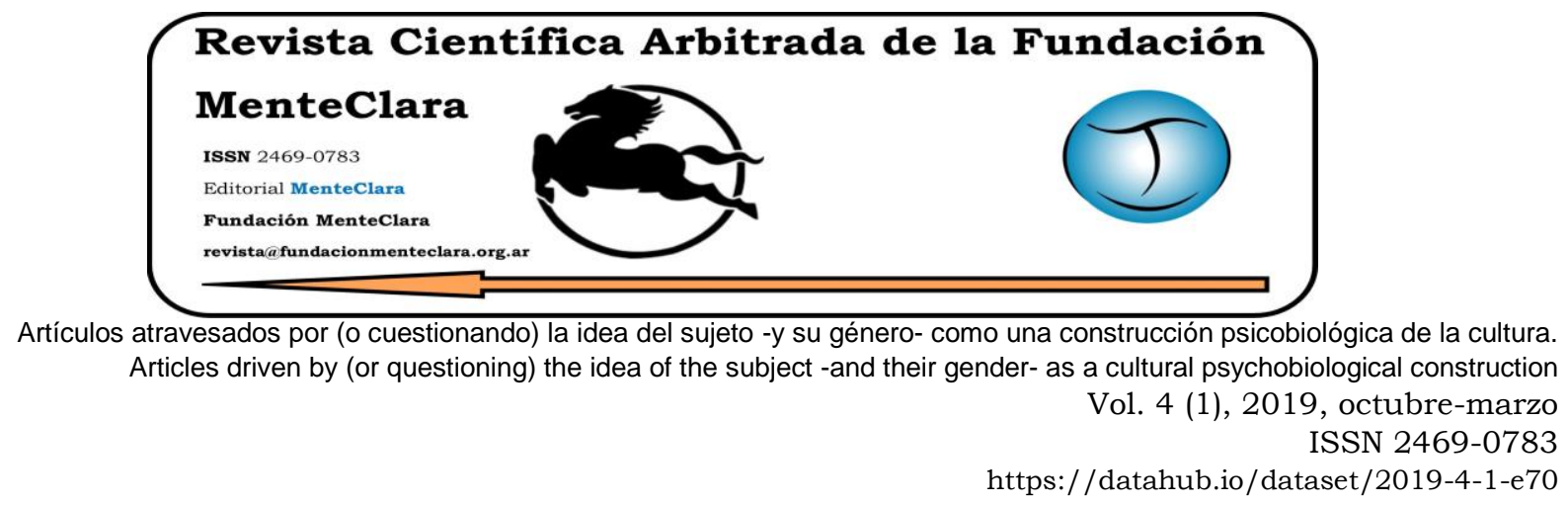

\title{
ACCESS DENIED? : CULTURAL CAPITAL AND DIGITAL ACCESS
}

\author{
¿ACCESO DENEGADO? : CAPITAL CULTURAL Y ACCESO DIGITAL
}

Shraddha Kumbhojkar'1, Rahul Magar², Shantanu Ozarkar ${ }^{3}$

Cómo citar este artículo / Citation: Kumbhojkar S., Magar R. \& Ozarkar S. (2019).

"Access Denied? : Cultural Capital and Digital Access". Revista Científica Arbitrada de la Fundación MenteClara, 4(1) octubre-marzo 2019, 65-78.

DOI: https://doi.org/10.32351/rca.v4.1.70

Copyright: () 2019 RCAFMC. Este artículo de acceso abierto es distribuido bajo los términos de la licencia Creative Commons Attribution 4.0 International License (CC BY 4.0). Recibido: 10/03/2019. Aceptado: 17/03/2019 Publicación online: 30/04/2019

Conflict of interests: None to declare.

Was funded By: The research work for this paper has been conducted out of a grant received from the Center of Social Sciences and Humanities, Savitribai Phule Pune University to the Center for Asian Studies.

\begin{abstract}
The paper is a micro-level quantitative study of perceptions of social science students in India whether Free Wi-Fi has helped them learn better. It is commonly believed that digital resources are neutral about social inequalities. However, the survey finds that socio-cultural capital in the form of Caste, Gender, Language and Location has a negative impact on digital access even if it is free. The paper also instills hope as it finds that almost every student on the campus of a State University in Western Maharashtra has access to the Internet and majority of these students perceive that the digital access has improved their academic performance.
\end{abstract}

\footnotetext{
${ }^{1}$ Savitribai Phule Pune University, Assistant Professor, Dept of History. India. shraddha@unipune.ac.in

${ }^{2}$ Savitribai Phule Pune University, Research Student, Dept of History. India

${ }^{3}$ Savitribai Phule Pune University, Assistant Professor, Dept of Anthropology. India
} 


\section{Resumen}

Este artículo es un estudio cuantitativo a nivel micro de las percepciones de los estudiantes de ciencias sociales en la India sobre si el Wi-Fi gratuito les ha ayudado a aprender mejor. Se cree comúnmente que los recursos digitales son neutrales sobre las desigualdades sociales. Sin embargo, la encuesta revela que el capital sociocultural en forma de casta, género, idioma y ubicación tiene un impacto negativo en el acceso digital, incluso si es gratuito. El documento también infunde esperanza, ya que encuentra que casi todos los estudiantes en el campus de una Universidad Estatal en Western Maharashtra tienen acceso a Internet y la mayoría de estos estudiantes perciben que el acceso digital ha mejorado su rendimiento académico.

Palabras Claves: internet; wi-fi universitario; castas; exclusión; segregación Keywords: Internet; university wi-fi; castes; exclusion; segregation 


\section{Introduction}

Every third Indian has access to the internet through her phone. The number of mobile internet users in India today is much higher than what was the total population of India in its first census of $1951^{1}$. So, what are the Indian historians doing about it? The answer probably can be found if we approach the elephant of Digital Humanities in our room. A good beginning would be to recognise that Digital Humanities is a branch of knowledge with which historians can share some synergies.

Digital Humanities (DH) is a field that tries to understand the interactions between the Science of human behaviour and the Technology of digital nature. Its definition is still evolving, but here are a few descriptions $^{2}$. Digital humanities is an umbrella term that covers a wide variety of digital work in the humanities: development of multimedia pedagogies and scholarship, designing \& building tools, human computer interaction, designing $\&$ building archives, etc. DH is interdisciplinary; by necessity it breaks down boundaries between disciplines. It is an academic field self-reflexively looking at the application of digital technology to humanities fields of enquiry.

\section{Approach}

In this paper we are proposing that an alliance between History and DH can be approached in two ways. First, meaningfully engaging our computational abilities with the historical research we may be engaged in. For historians, this may involve digitisation of archives, digitally recording the living traditions, 3-D printing and imaging of rare artifacts or virtual mapping of heritage sites, possibilities are endless. In fact, many of these have already become a part of a day in the life of any person with a Smartphone. As regards the second approach, historians can 
boast of being the experts, as they already have the domain knowledge to understand the impact of novel and what are called as "disruptive" technologies on human interactions. In this second approach, the historians' expertise can be used to understand, analyse and explain the effects of digital technology on various aspects of our lives - ranging from increasing obesity and divorce rates to decreasing leisure time and attention spans. Thus, the interaction between History and Digital Humanities has two sides to it. The first and the more visible side uses computational techniques at every stage of historical research and its dissemination. Second and more unexplored side is using the historical research method to understand the changes brought about by the digital realities in the society we study. It is this second approach which is employed in this paper to understand the effects of free Wi-Fi connectivity on the students' perceptions about their academic achievements.

\section{Background}

The National Convention on Digital Initiatives for Higher Education was a convention attended by more than 700 Vice-Chancellors of Indian Universities. At this convention held on $9^{\text {th }}$ July 2017, a platform for digital learning was launched by the President of India while the Cabinet Minister and the Minister of State for Human Resource Development were the guests of honour. An Action Plan called 17 by $17-17$ points to be achieved by the end of 2017 - was adopted at the convention. It included points such as digitisation of libraries and campus processes and monitoring of the current usage of digital resources and the like ${ }^{3}$. Though availability of high speed internet access was not mentioned in the action plan, on 15 January 2018, the Ministry of HRD issued a letter to all the Vice-Chancellors of Indian Universities that stated that "Digital Campus presupposes existence of high speed internet access and Wi-Fi facility 
that would help all the students/ faculty to access the same from their laptop/ mobile». It further advised the universities to take up a larger national effort involving both private and public players and asked them to make Wi-Fi connectivity available in all higher education institutions by $15^{\text {th }}$ August $2018^{4}$.

20 years before these developments, in 1997, Savitribai Phule Pune University $^{5}$ (SPPU) founded its Centre for Network Computing (CNC) for maintenance of a Campus-wide Network for the use of the Universityincluding students, teachers and the administration. ${ }^{6}$ Since 2014, Optical Fibre Based Wi-Fi access is available free of cost for all bonafide students, teachers and the staff of SPPU throughout its 400 Acre campus of the University including study areas, hostels, canteens and gardens. As SPPU campus has a fairly established system of free Wi-Fi for all, which has been fully functional since 2014, a study of the effects of this digital initiative, it is hoped, might offer some insights for the Indian Universities that are now taking up the Digital Initiative at the behest of the Ministry of HRD.

\section{Methodology}

While a comprehensive study of students representing all faculties of higher education would be a more desirable option, limited availability of sample, time and resources has prompted the choice of social science students at the Savitribai Phule Pune University as the universe of respondents for the present study. This choice is based on the fact that in India, the maximum number of students at the graduate and the post graduate level are enrolled in Social Sciences as per the AISHE 2015-167. Also, $94 \%$ of the students taking higher education in India are enrolled in state universities ${ }^{8}$ such as SPPU. The sample of respondents in this 
study therefore, can be considered as representative of a number of groups, such as students of 367 State Universities, Indian students taking post-graduate education, first generation of students enjoying free Wi-Fi and youth in developing countries.

The study is based on the findings of a questionnaire based survey conducted in February 2018 using a Convenient Sample of 217 social science students of SPPU in an attempt to understand how access to free Wi-Fi impacts them.

\section{Objectives}

Some of the objectives of this study are as follows -

1. To evaluate the impact of Wi-Fi Access on the Social Science Students of SPPU.

2. To assess if the students perceive any correlation between Free WiFi Access and Learning Outcomes.

3. To assess the extent to which students use the Wi-Fi connectivity for accessing subscribed e-journals.

4. To assess the factors affecting the effective academic use of free wifi by the students.

5. To suggest possible policy measures for effective utilisation of wi-fi network and other resources.

The research project began in September 2017 and a structured questionnaire was administered to a total of 217 students from 9 departments that constitute the social sciences at SPPU. 


\section{Hypotheses}

The study was undertaken to verify if the following hypotheses can be proved.

1. Students feel that they have benefitted academically from the free Wi-Fi access on SPPU campus.

2. The difficulties in getting access to the $\mathrm{Wi} F i$ network are correlated with the caste, gender and language of instruction of the students.

3. Majority of students do not use academic publications that can be accessed free of cost through the University Wi-Fi.

4. The non-use of academic publications is also correlated with the caste, gender, availability of resources and language of instruction of the students.

5. While Digital technology touches and improves the academic performance of the students across all strata, the difference in their achievements is correlated with non-academic and nontechnological factors such as caste, location, language and gender.

\section{Discussion}

Here are some relevant markers of the respondents' profile. With 102 females, 1 transgender and 114 males, the Gender Parity Index (GPI) of the respondents stands at $0.89 .991 \%$ students are Indian and most of the remaining students are from other Asian and African countries. $65 \%$ of the total students belong to the First year and $35 \%$ belong to the Second year of post-graduation. 83\% of them are between 20 to 25 years of age, though few students are older, between 25and 50 years of age. 65 
$\%$ of the respondents have completed their schooling with Marathi as the medium of instruction. At the University, however, $66 \%$ have chosen English as their medium of education. Of the $84 \%$ respondents who have chosen to disclose their religion, $77 \%$ are Hindu, 8.2\% are Christian, 6.5 $\%$ are Muslims and $5 \%$ are Buddhists. The category-wise composition of the respondents is as follows. General - 36.9\%, Other Backward Castes - $22.1 \%$, Not Answered 12.9\%, Scheduled Castes - 10.6\%, Scheduled Tribes- 10.6\%, Nomadic Tribes - 6\% and De-notified Tribes - 0.9\%. These details are furnished so as to indicate the caste, religious and social profile markers of the students.

As for the digital profile of the respondents, $99 \%$ have answered that they do have access to the internet, and only $14.6 \%$ have begun using the internet recently, i.e. since joining the university. Mobile revolution is obvious and visible in this sample as $92.6 \%$ respondents have their own smartphones and use them for accessing the internet. However, the number of laptop owners is also not insignificant at $44.7 \%$. While smartphones are owned by practically everybody, laptops being an expensive resource are owned by the respondents with various kinds of advantages. For example, only $18.1 \%$ Marathi medium students have their own laptops as against 58 \% English medium students. $58.8 \%$ Open category students own laptops as against 0 DT, $13 \%$ SC and close to $31 \%$ each of NT and OBC students. A gender based review of laptop owners surprisingly shows that a bigger percentage of owners - 55.7\% are girls as against the boys $-44.3 \%$. This can be explained by the social reality that of the girls that own laptops $50 \%$ belong to the open category and a further $24.1 \%$ have not disclosed their castes. $89 \%$ of these girls have chosen English as the medium of instruction and $63 \%$ of these laptop owning girls come from cities and metros. 
Access to the internet is almost universally (99\%) available for SPPU students and this is a very encouraging fact. However, of these internet users, only $69 \%$ are connected with the free SPPU Wi-Fi while the others have to pay the private companies for getting access to the internet through Wi-Fi. This can be seen as an important leak as a big number of students are not able to use or are choosing not to use the SPPU Wi-Fi. Of these non-users of SPPU Wi-Fi, $63 \%$ are women. $49 \%$ belong to the open category and a further $16 \%$ have not disclosed their category. $76 \%$ of these non-users of SPPU Wi-Fi have chosen English as their medium of instruction. $58 \%$ of the non-users are day scholars. Thus, non-users of SPPU Wi-Fi are likely to be women, of the general category, i.e. high castes, have chosen English as their medium of instruction and are staying out of campus. It may be argued that majority of non-users of SPPU Wi-Fi are privileged - a situation similar to the subsidized health care system of government hospitals. However, that does not mean that the difficulties that are preventing the non-privileged users from accessing SPPU Wi-Fi need not be addressed.

If one attempts to understand what could be the circumstances leading to what may be called digital deprivation of the students, the reasons are surprisingly commonplace - gender, caste, language, social background - lack of cultural capital. One would imagine that the digital resources at least would be culture neutral, but as the present study shows, they are not. Just like all other vital resources such as water, food, land, health and education - digital access is also correlated with the cultural capital of the users. The survey numbers point to this conclusion.

When asked if they faced any difficulties while getting access to the SPPU Wi-Fi, half of them said they had faced difficulties while getting access to the SPPU Wi-Fi. The respondents pointed to various process based reasons for these difficulties. They stated that the process of getting 
access is time consuming and complicated. One respondent complained that it took one month to get access to the SPPU Wi-Fi. Lack of coordination between the academic departments and the CNC was also pointed out by some respondents. These process based reasons should have been faced by all students equally in a neutral scenario. Here, it was found that while only $21 \%$ of the open category students faced difficulties in getting access to the SPPU Free Wi-Fi, 47\% SC, $43 \%$ OBC, $43 \%$ ST, and $61 \%$ NT students faced these same difficulties. 50\% Urdu medium, 38.6\% Marathi medium and $32 \%$ English medium students faced difficulties. Similarly, $19.2 \%$ students coming from metro cities faced difficulties as against $45.9 \%$ students from villages. In terms of gender, however, $24.5 \%$ women and 43.9\% men faced the initial difficulties. The joy is not long-lived considering the fact that more than $43 \%$ women are in the Not Applicable Category - which means they have already chosen not to use SPPU Wi-Fi. In case of the ownership of a laptop, which is a fairly expensive gadget, $58.8 \%$ of the general category students owned a laptop, while only $13 \%$ SC and $31 \%$ OBC students actually own it. 25 $\%$ Marathi medium and 78\% English medium students own them. Thus, it is observed that caste and medium of instruction do exert their influence on the first essential step - that is the access to free Wi-Fi for the students.

The patterns of usage of SPPU Wi-Fi are indicative of the impact of free access to the internet on the students. $9 \%$ students claimed they did not know anything about the scheme called Vayudoot Student- which is the name of the network to be used by students of SPPU. Out of the $99 \%$ students with access to the internet, this is not an insignificant number. These $9 \%$ can be called the first victims of ignorance as they do not know anything about the network that can give them free internet access. The divide further widens as $32 \%$ students admit that they do not use SPPU 
Wi-Fi, though they are very much connected to the internet. This gets worse as $55 \%$ students confess that they do not use any e-books or ejournals through the SPPU Wi-Fi. The reason becomes obvious because only $48 \%$ respondents were aware that the SPPU has subscribed to ejournals and purchased e-books for the students to use. Furthermore, only $33 \%$ have said that they use the subscribed e-books and e-journals. Of these users of subscribed resources, $8.3 \%$ said they used them daily and $11.5 \%$ said they used them once a week. Remaining $80 \%$ used it infrequently. When the respondents were asked to name 3 e-books or ejournals subscribed by the university, very few resources that are actually subscribed by the SPPU were named. The respondents named popular publications such as newspapers or websites catering to the applicants for competitive examinations for getting government jobs and other such sites, or resources that are available on the web free of cost. Very few names of recognised resources and databases that have been actually subscribed by the SPPU were named by the students - for example Jstor and Economic and Political Weekly. This dismal state of underutilization of resources obviously demanded enquiry into the reasons why the students did not use the means at their disposal to read the latest research in the field of their choice.

Even if the students have got the access to the University Wi-Fi, why are they using the subscribed e-resources in such few numbers? More than $86 \%$ of the students have listed out their lack of awareness as a major reason for not using the e-resources from the University Wi-Fi. However, when we carefully examine and cross-tabulate the social and cultural markers of the students, it confirms the correlation between cultural capital and utilization of resources. Of the total students who have said that they do use the subscribed e-resources, a major chunk$41 \%$ are from the general category and only $8 \%$ SC-, $12 \%$ ST and OBC 
$19 \%$. In spite of being on the wrong side of the digital divide, many students have expressed that they feel that SPPU Wi-Fi has improved their academic performance (66\%), their presentation (73\%) and their marks (49\%). They are of course not content with what has been given to them and have suggested a number of ways for improved access, as well.

\section{Conclusions}

1. Free Wi-Fi Access has had a definitely positive impact on the Social Science Students of SPPU.

2. The students perceive a positive correlation between Free Wi-Fi Access and Learning Outcomes.

3. Students' use of the Wi-Fi connectivity for accessing subscribed eresources has a lot of scope for improvement.

4. Effective academic use of free Wi-Fi by the students can be assured by creating better awareness about the available sources among the students as well as their teachers.

5. Better awareness and a society based on equality would be conducive to the effective utilisation of Wi-Fi network and other resources by the students.

Thus, the study of the digital experience undertaken with a historical approach helps us understand why some people are more equal than others even as it is claimed that there is a democratization of knowledge because of the internet and the digital technology. The takeaway for a historian from this case study could be that the digital reality is definitely altering the lives of humans even as the entrenched socio-cultural realities are affecting the digital experience of the individual. As more and 
more such studies are conducted by historians, it will be possible to comprehend the relationship between the digital reality and human life. 


\section{References}

1 http://censusindia.gov.in/Census_Data_2001/India_at_glance/variation.aspx accessed 16-11-2018. 36.1 Crore people in 1951. https://yourstory.com/2018/03/mobileinternet-users-india-reach-478-million-june-2018-iamai-report/ accessed 16-11-2018. 45.6 Crore users in 2017.

2http://www.artsrn.ualberta.ca/taporwiki/index.php/How_do_you_define_Humanities_Co mputing_/_Digital_Humanities\%3F accessed on 20-11-2018.

${ }^{3}$ https://www.aicte-india.org/downloads/17by17.pdf accessed on 28 March 2018.

4http://www.aicte-india.org accessed on 28 March 2018.

IIt was then known as University of Pune and has been renamed since 2014.

${ }^{6}$ Interview with Professor Anjali Kshirsagar, Retd Head, Dept of Physics, SPPU. 10-1-2018. She led the next level of the CNC to provide wi-fi connectivity through optical fibres.

7http://mhrd.gov.in/sites/upload_files/mhrd/files/document-reports/HRD_AR\%20201617.pdf P. 153. accessed on 28 -03- 2018

8 B. Benkatesh, Ashok Thakur, A Game-Changer for Higher Education, in The Hindu, 2803-2018. Accessed from http://www.thehindu.com/opinion/op-ed/a-game-changer-forhigher-education/article23366942.ece?homepage=true on 28-03-2018.

9 GPI is the ratio of female to male respondents and a less than 1 GPI indicates disparity in genders. Here 0.89 GPI means there are 89 female students to every 100 male students from our sample. It may be noted that women do not have any reservation at the level of $\mathrm{P}-\mathrm{G}$ admission as per the Government of Maharashtra rules. 